\title{
Development of a comprehensive monitoring and auditing tool for oxidation ponds systems in the Middle Vaal and Upper Orange catchment areas
}

\author{
U Jack ${ }^{1 *}$, G Mackintosh', C Jagals ${ }^{2}$ and J van der Merwe ${ }^{2}$ \\ ${ }^{1}$ Emanti Management (Pty) Ltd, PO Box 1264, Stellenbosch 7599, South Africa \\ 2 Water Quality Management, DWAF Free State, PO Box 528, Bloemfontein 9300, South Africa
}

\begin{abstract}
An investigation of the current status of municipal sewage pond systems in the Free State region was undertaken to provide the Department of Water Affairs and Forestry (DWAF) Free State Regional Office with a strategic decision support tool to evaluate the current status of sewage pond systems in order to provide base-line information required by the Department. This will also contribute to a healthy environment by ensuring that strategic environmental issues associated with sewage systems are identified and that potential strategies for impact minimisation and prevention are implemented. This paper provides feedback on the background to the study, literature review conducted, the tool developed that can be utilised to assess pond systems and its outputs. This tool must be seen as a positive evaluation tool to ensure good management of pond systems to promote a healthy environment.
\end{abstract}

Keywords: waste stabilization ponds, health, environment

\section{Introduction}

In the Free State Province of South Africa municipal wastewaters are principally treated via activated sludge plants, trickling filter plants, rotating biological contactors (RBCs) and pondbased systems. A significant proportion of the municipal wastewater systems in the Free State are pond-based, with some 45 systems utilising waste-stabilisation ponds alone, and an additional 15 systems utilising ponds with additional unit processes (e.g. trickling filters) (i.e. a total of 60 pond based systems in the Free State). These waste-stabilisation pond systems, referred to as oxidation ponds, have for many years provided an effective and low-unit cost means of handling domestic wastewater from the smaller communities of the Free State. The waste-stabilisation ponds of the Free State have generally performed well for many years, effectively preventing environmental pollution and associated health impacts. Nevertheless, recent concerns have arisen as to the current operational state of waste-stabilisation ponds of the Free State and their impact on both the natural environment and human health.

An indication that problems exist within pond systems could include the following:

- Complaints relating to the failure and/or poor condition of waste-stabilisation ponds

- Indications of intent to take legal action against local authorities because of the poor conditions that exist at pond systems and the associated environmental and health impacts

This paper was originally presented at the 2006 Water Institute of South Africa (WISA) Biennial Conference, Durban, South Africa, 21-25 May 2006

* To whom all correspondence should be addressed.

푱+2721 880-2932; fax:+2721 880-2931; e-mail: unathii@emanti.co.za
- Insufficient information regarding the operational status of waste-stabilisation ponds, and the effectiveness of the management thereof by local municipalities.

As the designated water sector leader tasked with inter alia regulatory oversight of the water services sector, the Free State DWAF office determined to initiate a study into the waste-stabilisation ponds of the Free State. In brief, the focus of the study was to:

- Determine and document the current status of waste-stabilisation ponds in the Free State

- Develop a simple strategic decision support tool to guide interventions as may be required.

Experiences gained and best practice guidelines from the study are presented in this paper. They could thereafter be directly utilised by Water Services Authorities (WSAs), DWAF and other government institutions (e.g. Department of Local Government and Housing (LGH), Department of Health, etc.) and industries to assist in effective management of pond systems throughout the Free State.

\section{Objectives}

This paper is aimed at providing assistance to WSAs, for better management of pond systems. In achieving this, the following will be briefly described:

- Literature review

- Process followed to conduct the study

- Development of the scoring and risk assessment tools

- Outputs of the tool

- Issues of concern.

The following sections report on the key issues from the literature. The development of both an Excel-based tool for 
performance scoring of sewage ponds, and an Excel-based tool for the risk profiling of sewage ponds were developed are reported. The outputs of the tools developed are also presented.

\section{Methodology}

\section{Literature review}

The main purpose of the study was to provide DWAF Free State with a strategic tool to evaluate the current status of the sewage pond systems, thereby providing a base line of information from where immediate interceptive actions can be taken. Furthermore, the tool will assist in ensuring that strategic environmental issues associated with waste-stabilisation pond systems are identified and that potential strategies for impact minimisation and prevention are implemented.

The nomenclature used in describing pond systems can be confusing, and a common terminology is useful. The literature generally describes a pond based treatment system as a 'waste-stabilisation pond system'. Waste-stabilisation pond systems comprise a series of ponds, all of which are relatively shallow bodies of wastewater contained in an earthen basin. The primary pond is often an anaerobic pond, followed by a series of aerobic ponds. Anaerobic ponds provide a degree of pre-treatment, thereby enabling a reduction in the size requirements of the subsequent aerobic ponds. As regards aerobic ponds, these all operate in the presence of air or oxygen, and there are essentially five types of aerobic ponds (Eckenfelder, 1989) viz.:

- Oxidation ponds

- Mechanically assisted ponds

- Aerated oxidation ponds

- Facultative ponds

- Suspension mixed aerated lagoons.

Waste-stabilisation ponds are used extensively for treatment of domestic wastewater and mixtures of industrial and domestic wastewater where amenable to biological treatment by natural processes involving the use of algae and bacteria (Metcalf and Eddy, 1991). The objectives of the biological treatment of wastewater are to coagulate and remove the non-settleable colloidal solids; to stabilise the organic matter, and to produce an effluent of acceptable quality.

Importantly, waste-stabilisation ponds have some critical advantages compared to other forms of wastewater treatment which include the following (Mara, 1976):

- Ponds can achieve the required degree of purification at lowest cost and with minimum maintenance by unskilled process controllers

- The removal of pathogens is considerably greater

- They are well able to withstand both organic and hydraulic shock loads

- They can effectively treat a wide variety of industrial and agricultural wastes

- They can easily be designed so that the degree of treatment is readily altered

- The method of construction is such that, should at some future date the land be required for some other purpose, it is easily reclaimed.

Disadvantages of waste stabilisation ponds include the following (Environmental Protection Agency (EPA) online):

- The need to clean out accumulated solids

- May produce undesirable odours
- The inability of the ponds to remove small-sized particles

- They require a large piece of land.

The following aspects have been mentioned by Metcalf and Eddy (1991) to be of importance when dealing with pond systems:

- Design

- Operation and performance

- Maintenance

- Safety.

Hence the development of an Excel scoring tool included also these aspects. The considerations around those aspects are shown in Table 1.

\section{Development of Excel-based waste-stabilisation pond-scoring tool}

The detailed on-site assessment was conducted using the considerations in the table. The field observations were then loaded onto the Waste-stabilisation pond scoring tool i.e. a spreadsheet based decision support tool utilising a scoring/weighting system and the outcomes thereof are critically considered. The spreadsheet based tool contains the following main categories for which points were allocated to provide an overall score for a waste-stabilisation pond system:

- Design

- Maintenance

- Operation and performance

- Safety

- Supervision and management

- General authorisation.

The evaluation criteria developed for the above categories are shown Table 1. Using this score, the various pond systems were ranked.

An example of typical outputs for the scoring tool is shown in Fig. 1: a percentage score is calculated from the scores obtained for each category and plotted against that category.

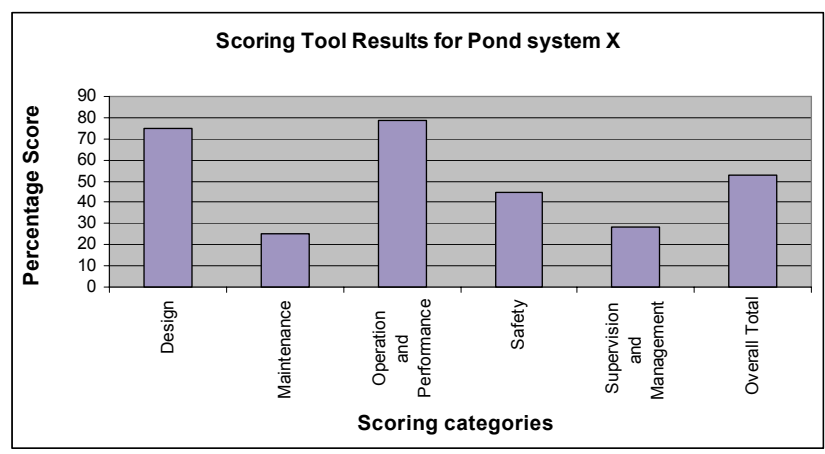

Figure 1

Scoring tool outputs example (for an individual system)

If an assessment is conducted for more than one pond system and the results for each category are compared against each other, the following graph is obtained (Fig. 2, p. 658).

\section{Development of Excel-based waste-stabilisation ponds risk profiling tool}

The importance of differentiating between the general status of a waste-stabilisation system, and the risk associated with that 


\begin{tabular}{|c|}
\hline $\begin{array}{c}\text { TABLE1 } \\
\text { Questions used to assess status of waste stabilisation ponds }\end{array}$ \\
\hline 1. Design (max score) \\
\hline 1.1 Are the ponds properly lined for their purpose? \\
\hline 1.2 Does the pond meet recommended depth criteria ( 1.0 to $1.5 \mathrm{~m}$ for oxidation and $3 \mathrm{~m}$ for anaerobic)? \\
\hline 1.3 Is the design capacity of the pond known? \\
\hline 1.4 Is the size of pipes suitable for their effluent volumes? \\
\hline 2. Maintenance (max score) \\
\hline 2.1 Do the ponds appear well maintained? \\
\hline 2.2 Are verges clear of grass? \\
\hline 2.3 Are screenings maintained regularly \\
\hline 2.4 Are the screenings buried or taken to a suitable dumping site \\
\hline 2.5 Are there prescribed maintenance procedures \\
\hline 2.6Is there any algal growth or slime layer removal \\
\hline 2.7 Has the pond ever been drained and dislodged \\
\hline 3. Operation and performance (max score) \\
\hline 3.1 Is there a flow meter at the inlet \\
\hline 3.2 Is it likely that the ponds may impose health hazards e.g. flowing to a stream, smells, flies \\
\hline 3.3 Is there an abattoir waste received in the pond \\
\hline 3.4 Is the interconnection between the ponds clear and safe \\
\hline 3.5 Do the ponds have a free board of $0.5 \mathrm{~m}$ \\
\hline 3.6 Is dilution water available for night soil dumping \\
\hline 3.7 Is the pond overloaded (hydraulically /biologically) \\
\hline 3.8 What is the type of effluent to be treated \\
\hline 3.9 Are there any boreholes near the ponds \\
\hline 3.10 Are the boreholes monitored \\
\hline 3.11 Is there a space for upgrading \\
\hline 3.12 Is there population growth (rapid/slow) \\
\hline 3.13 Is a report produced highlighting issues of concern (e.g. malfunctions, mechanical failures) \\
\hline 4. Safety (max score) \\
\hline 4.1 Is the site enclosed (fences, gates and locks) \\
\hline 4.2 Are there 'no trespassing' and health warning signs \\
\hline 4.3 Are prescribed safety procedures adhered to \\
\hline 4.4 Do staff have necessary safety clothing and equipment \\
\hline 4.5 Is there any public awareness of safety aspects \\
\hline 4.6 Are the ponds located at a recommended distance from the dwellings \\
\hline 4.7 Are there animals on site \\
\hline 5. Supervision and management (max score) \\
\hline 5.1 Have responsibilities been assigned for pond system, operation and maintenance \\
\hline 5.2 Is the responsible operator trained \\
\hline 5.3 Is a checklist/ logbook regularly completed or updated \\
\hline 5.4 Are the findings from the report discussed with appropriate LM water forums where all required duties are presented \\
\hline 5.5 Are actions required timeously implemented \\
\hline 6. General authorisation (max score) \\
\hline 6.1 Does the pond system have necessary permits \\
\hline OVERALL TOTAL SCORE \\
\hline
\end{tabular}

system was noted in terms of the different types of decisions that would need to arise.

In order to determine Waste-stabilisation Pond Risk, elements utilised in performing evaluations for Environmental Impact Assessments (EIAs) and ISO 14001 Environmental Management Systems (EMS) were adapted and utilised (CSIR, 2002). In summary, the following convention for the assessment of impact significance was used:

- Extent - This should indicate whether the impact will be local and limited to the immediate area surrounding the pond system $(<200 \mathrm{~m})$; limited to within $5 \mathrm{~km}$ of the ponds; or whether the impact may be realised regionally or even nationally.

- Duration - This should review the lifetime of the impact, as being short term (0 to 1 year), medium ( 2 to 5 years), long term $(>5$ years but where the impacts would cease if the pond system was not utilised), or permanent.

- Intensity - Here it should be established whether the impact is destructive or innocuous and should be described as low (e.g. no environmental or human functions and processes are affected), medium (e.g. the environment and human activities continue to function but in a modified manner) 


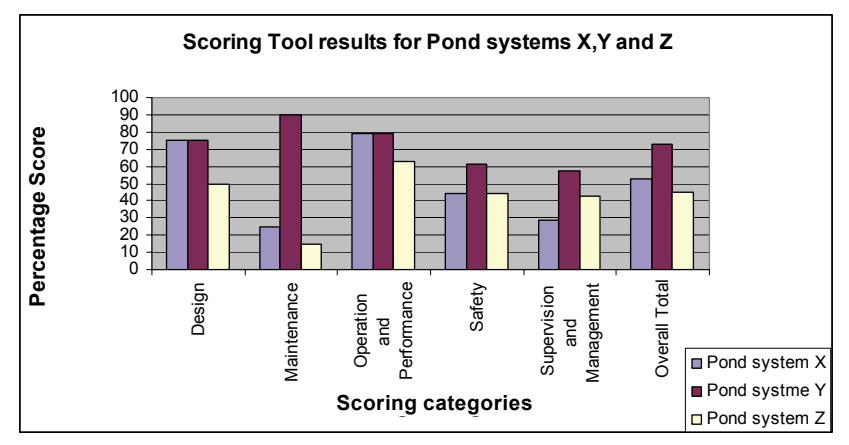

Figure 2

Scoring tool outputs example (for more than one system)

or high (e.g. environmental and human functions and processes are altered such that they are temporarily or permanently impaired).

- Probability - This considers the likelihood of the impact occurring and should be described as improbable (low likelihood), probable (distinct possibility), highly probable (most likely) or definite (impact will occur regardless of prevention measures).

- Degree of confidence in predictions - The degree of confidence in the predictions, based on the availability of information and specialist knowledge.

In order to quantify the relative significance of the above potential risks, an ISO 14001 based scoring process can be used. The following scoring convention is suggested using four categories (maximum score of 40): The four categories are:

- Maintenance risk - impact arises when the ponds are not well maintained

- Management risk - impact arises when there is no assignment of responsibilities or checking of tasks completed

- Engineering risk - impact arises when the ponds are poorly designed

- Exposure risk - impact arises when the site is not enclosed.

The risk scores can be interpreted as follows:

- 0 to 10: Low negative health and environmental impact

- > 10 to 20: Medium negative health and environmental impact

- > 20 to 40: High negative health and environmental impact.

Table 2 illustrates how environmental impacts associated with a pond system could be scored using the aforementioned methodology. The scores are given according to the site observations and the interviews with responsible people.

Looking at Fig. 3, the risks associated to operator's exposure can be deduced by looking at such factors as:

- Does the staff have necessary protective clothing (e.g. masks, gloves, etc.)

- For how long are the operators exposed to bacteriological contaminated water

- Do they have shelter and designated rooms for eating.

\section{Results}

The results of the assessment carried out in the Free State can be considered a representation of the status of pond systems in South Africa. The results of the assessment carried out using the tool described above are presented in a stepwise manner in this section.
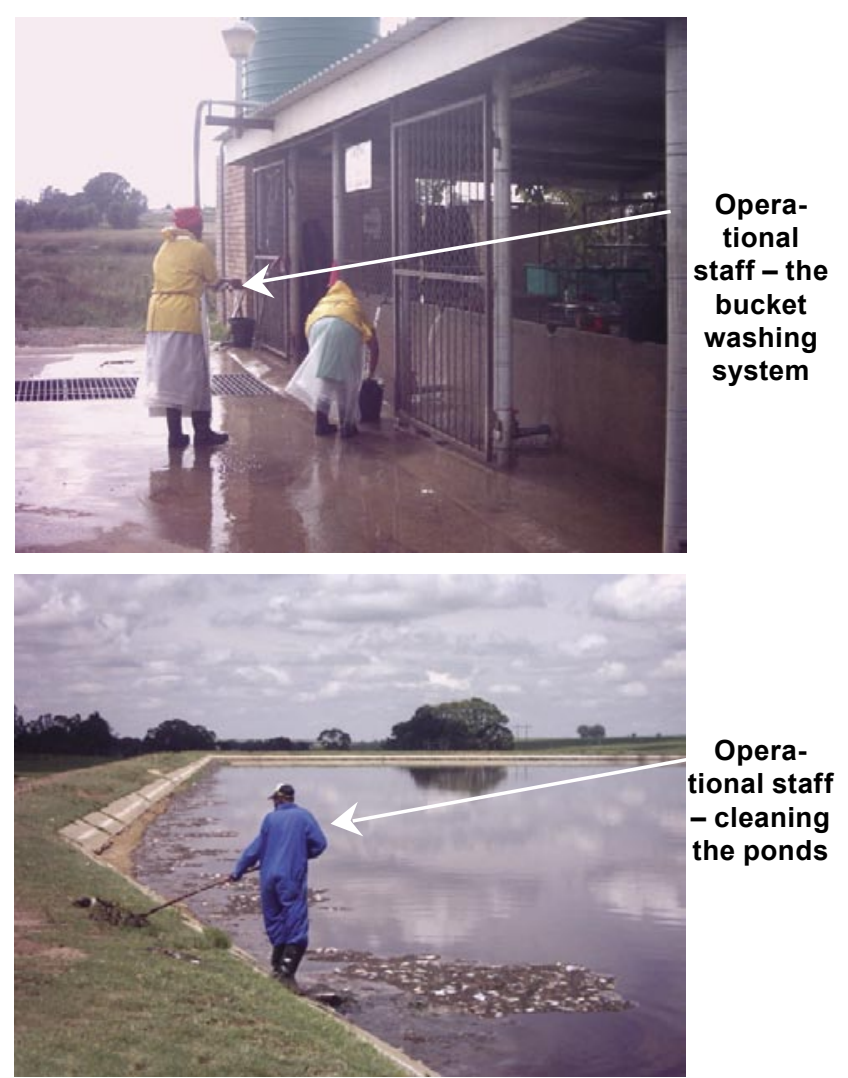

Figure 3

Indication of risks associated to exposure

\section{Design}

Free State waste-stabilisation ponds scoring with respect to design is generally good. In all the District Municipalities, the average percentage compliance is around $70 \%$.

\section{Maintenance}

Free State waste-stabilisation ponds scoring with respect to maintenance is generally very poor, with a small number of exceptions.

\section{Operation and performance}

For the criteria of operations and performance the ponds generally score reasonably well.

\section{Safety}

Free State waste-stabilisation ponds scoring with respect to safety are generally poor.

\section{Discussion}

This paper has shown that whilst waste-stabilisation ponds play a very important and appropriate waste-treatment function, they are in many instances failing in their primary objective of effective abatement of environmental pollution. Furthermore, in many instances unacceptable risk to human life and livestock also result principally from a combination of poor operational conditions (e.g. discharge to streams) and poor community awareness (children swimming in ponds). 


\begin{tabular}{|c|c|c|c|c|}
\hline \multicolumn{5}{|c|}{$\begin{array}{c}\text { TABLE } 2 \\
\text { Determination of environmental impact associated with pond systems }\end{array}$} \\
\hline \multicolumn{5}{|c|}{ 1. Engineering risk } \\
\hline & Max. score & Highest score & Ave. core & Min. score \\
\hline \multirow[t]{2}{*}{ 1.1 What could be the extent of the impact } & & High & Medium & Low \\
\hline & & 3 & 2 & 1 \\
\hline \multirow[t]{2}{*}{ 1.2 What could be the duration of the impact } & Permanent & Long-term & Medium term & Short term \\
\hline & 4 & 3 & 2 & 1 \\
\hline \multirow[t]{2}{*}{ 1.3 What could be the intensity of the impact } & & High & Medium & Low \\
\hline & & 3 & 2 & 1 \\
\hline SIGNIFICANCE OF IMPACT SCORE & & & & 6 \\
\hline \multicolumn{5}{|l|}{$\begin{array}{l}\text { PROBABILITY OR LIKELIHOOD OF ACCIDENT OR } \\
\text { ABNORMAL CONDITIONS }\end{array}$} \\
\hline \multirow[t]{2}{*}{ 1.4 What is the probability that there will be an impact } & Definite & Highly probable & Probable & Improbable \\
\hline & 4 & 3 & 2 & 1 \\
\hline $\begin{array}{l}\text { TOTAL SCORE (Significance of Impact*Likelihood of } \\
\text { occurrence) }\end{array}$ & & Medium & 12 & \\
\hline
\end{tabular}

\section{Maintenance}

Poor maintenance of the sewage pond systems is mainly due to the following practices and they are shown at the figures below:

- Screenings are not regularly removed both at the inlet and within the ponds.

- Screens are not buried or taken to the dumping site, instead are left on the banks of the ponds.

- Vegetation is covering or growing in-between the linings.

- Grass is growing long such that it is difficult to walk on-site.

\section{General safety}

The following factors were identified to be the key factors contributing to lack of safety and they are shown in the figures below:

- The sites are not well secured, that is, no fence or gates are left open

- In some cases the short-cut for the community is through the site

- Community is not well aware of the hazards of sewage pond systems

- Animals are deliberately kept on-site for grazing and drinking

- Fences, grid screens and houses are vandalised.

\section{Operator safety and facilities}

Operators were observed as on the whole being very poorly resourced in terms of operational equipment and the necessary protective clothing etc. Furthermore, operator facilities are sorely lacking at most pond sites as a result there are signs of vandalism on-site. The facilities to be provided for the pond operators depend partly on the staff number, but would normally include the following:

- First-aid kit (which should include a snake bite kit)

- Wash-basin and toilet, and the necessary soap

- Storage space for protective clothing, grass-mowing and scum-removal.

\section{Conclusions}

This initial study has successfully highlighted the status of pond systems in the Free State, with a clear indication of their

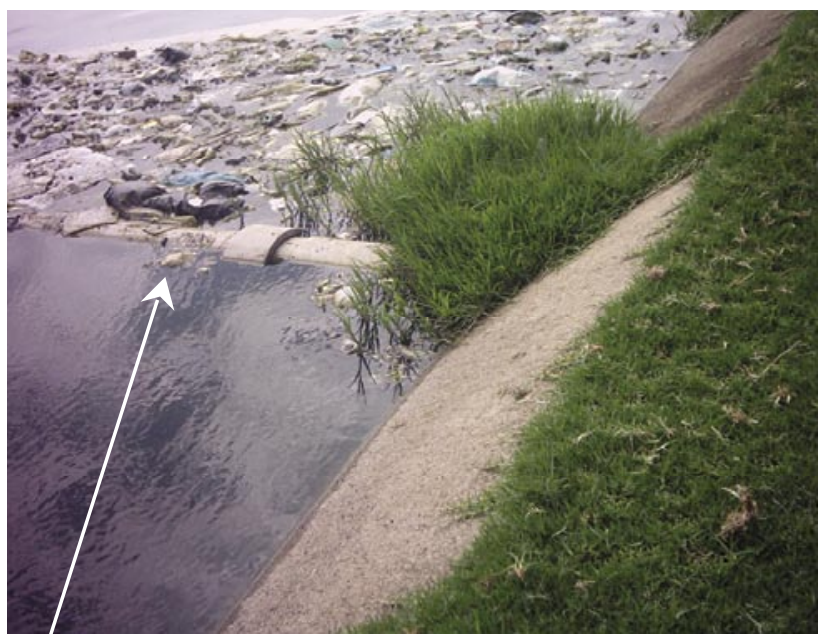

Pond clogged with solid waste

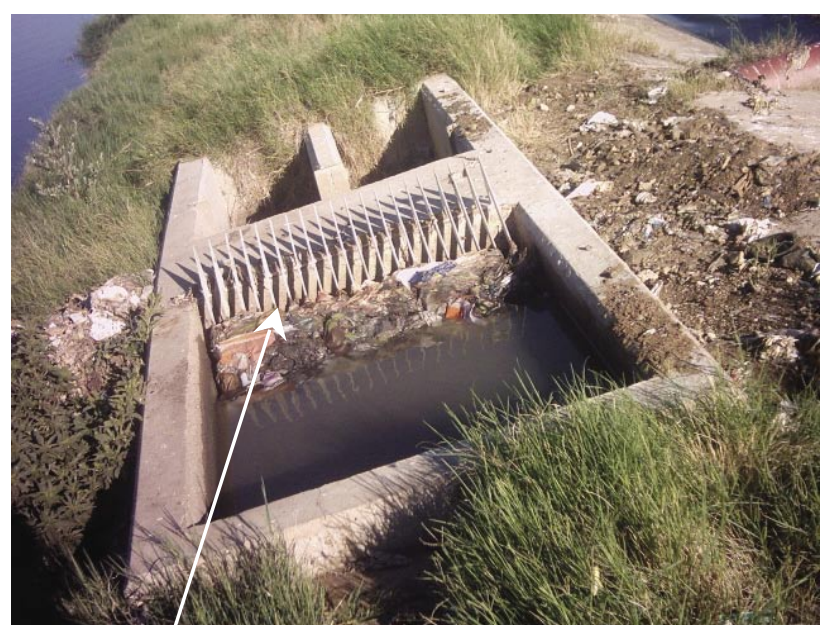

Inlet screens blocked

Figure 4 ( $a$ and $b)$

Factors contributing to poor maintenance

operational functioning and issues of concern. In essence the study has shown that many pond systems in the Free State are poorly maintained and lack appropriate safety and security measures. It is believed that this situation is not limited only to 


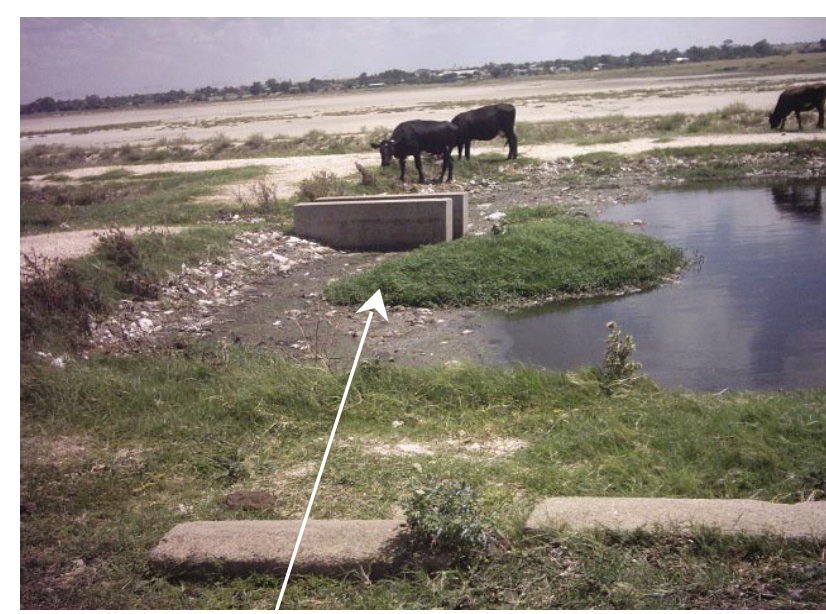

Ponds not fenced, animals grazing and drinking

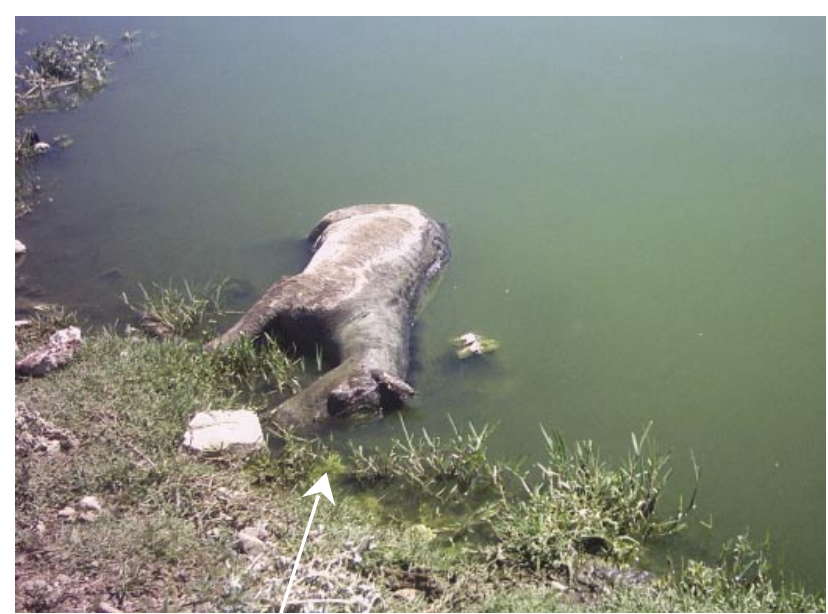

Dead animal within a pond

Figure 5 ( $a$ and $b$ )

Factors contributing to poor safety

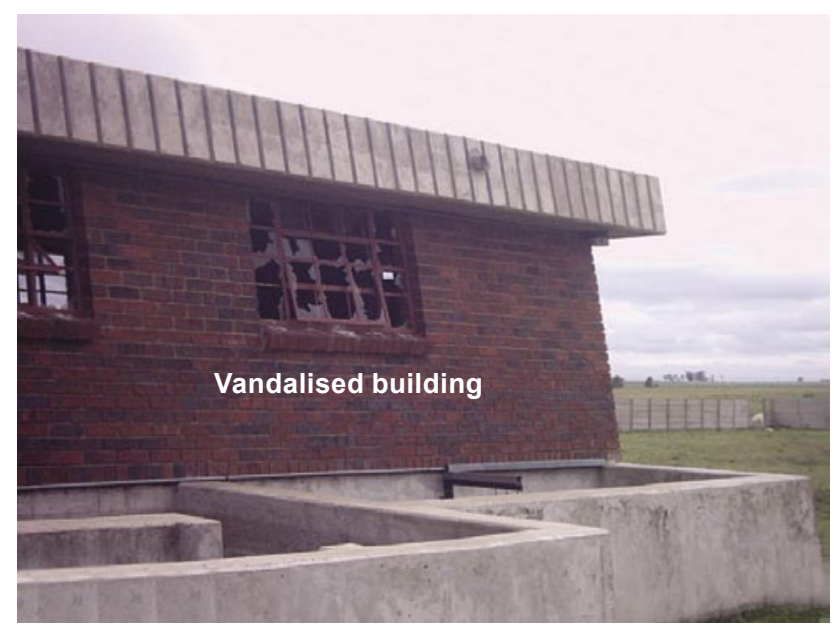

Figure 6

Signs of vandalism on pond site

pond systems in the Free State, but is indicative of the situation throughout South Africa where pond systems are used.

Follow-up studies are being conducted to further extend knowledge of pond systems in South Africa and to develop guidelines which could be used by Water Services Authorities (WSAs) to effectively operate and manage their pond systems.

\section{References}

ATLAS MRM and MOSBY RM (1995) Principles of Microbiology. Methods of Liquid Waste Treatment.

CSIR (2002) Report Reference: ENV-S-C 2002-092(B) Environmental Impact Assessment for the proposed Aluminium Pechinery smelter within the Coega Industrial Zone, Port Elizabeth, South Africa.

ECKENFELDER WW (1989) Industrial Water Pollution Control. $\left(2^{\text {nd }} e d n.\right)$. Biological Wastewater-Treatment Processes, Chapter 7. McGraw-Hill, Inc. Singapore.

ENVIRONMENTAL PROTECTION AGENCY (EPA) (2005) Wastewater Technology Fact sheet, Aerated, Partial Mix Lagoons. Available online: www.epa.gov/owm $/ \mathrm{mtb} / \mathrm{mtbfact.htm}$, accessed on $15 / 08 / 2005$

MARA DD (1976) Sewage Treatment in Hot Climates. John Wiley \& Sons, Ltd. Bath.

MARAIS GvR (1966) New Factors in the Design, Operation and Performance of Waste-Stabilization Ponds. World Health Organization. 33 737-763.

METCALF and EDDY (1991) In: Wastewater Engineering Treatment, Disposal and Reuse ( $3^{\text {rd }}$ edn.) Chapter 10. Revised by T George and LB Franklin McGraw-Hill, Inc. Singapore.

NGCOBO TC (1986) Stabilization Ponds. Unpublished B.Sc. (Eng.) degree Thesis, Department of Civil Engineering, University of Cape Town. 